\title{
Influence of Chitosan-Based Edible Coating on the Shelf Life and Nutritional Quality of Guava (Psidium guajava L.) Fruit in Room and Refrigerated Temperatures
}

\author{
Areeqa Shamshad 1, Shahzad Zafar Iqbal 2, Ahmad Faizal Abdull Razis ${ }^{3,4+}$ Sunusi Usman ${ }^{3}$, Nada Basheir Ali ${ }^{4}$, \\ Amina Mumtaz ${ }^{5}$, Muhammad Rafique Asi ${ }^{1}$
}

1 Plant Protection Division, Nuclear Institute for Agriculture and Biology, Jang Road Faisalabad, Pakistan

2 Department of Applied Chemistry, Government College University Faisalabad, Faisalabad 38000, Pakistan

3 Natural Medicines and Products Research Laboratory, Institute of Bioscience, Universiti Putra Malaysia, 43400 UPM Serdang, Selangor, Malaysia

4 Department of Food Science, Faculty of Food Science and Technology, Universiti Putra Malaysia, 43400 UPM Serdang, Selangor, Malaysia

5 Department of Biochemistry, Government College University Faisalabad, Faisalabad 38000, Pakistan*

Corresponding authors: shahzad10542005@yahoo.com (S.Z.I.); madfaizal@upm.edu.my (A.F.A.R.); Tel.: +92-300 7684577 (S.Z.I.); Tel.: +60-397693073 (A.F.A.R.)

\begin{abstract}
Guava is a vital fruit worldwide, especially in Pakistan, and due to its nutritional value famous in each age group. Due to a very short shelf life, the marketing and export of this fruit faced severe constraints. Therefore, in the current study, edible coating of chitosan $(0,0.5,1.0,1.5$, and $2.0 \%$ ) was evaluated on postharvest shelf life when guava fruits were stored (room temperature and $4{ }^{\circ} \mathrm{C}$ temperatures) for 12 days. The chitosan treated coating fruits have shown reduced total sugars and malondialdehyde levels compared to untreated control samples. However, a significant difference $(\mathrm{p} \leq 0.05)$ in total sugar and malondialdehyde levels exists between samples stored in $\mathrm{m}$ compared to refrigerated temperature $\left(4^{\circ} \mathrm{C}\right)$. The chitosan-coated samples have shown a greater amount of vitamin $C$, quercetin, rutin, and total phenolic contents than control samples. However, these nutritional parameters' levels were significantly different $(\mathrm{p} \leq 0.05)$ in samples stored at room than samples stored at refrigerated temperature. However, the levels of crude fiber, potassium, and sodium were found statistically nonsignificant $(\mathrm{p} \geq 0.05)$ in control versus chitosan treated coating treatments. The findings have documented that the coatings of 1.5 and $2.0 \%$ were most effective for extension in shelf life and maintaining the nutritional attributes of guava fruit.
\end{abstract}

Keywords: chitosan coating; edible coating; guava fruit; shelf-life; HPLC; flavonoids

\section{Introduction}

Guava (Psidium guajava L.) is an important fruit, and it belongs to the family of Myrtaceae. Guava fruit has great importance in Latin American countries like Colombia, Brazil, Mexico, Africa, and Asia [1-2]. It is cultivated on 62,300 with a production of 512,300 tons in Pakistan [3], and is ranked 4th in terms of total area production after citrus, mango, and apples [4]. Guava is composed entirely of minerals, vitamins. It contains $82 \%$ water, $0.7 \%$ protein, and $11 \%$ carbohydrates. It includes $2-6 \%$ more vitamin $C$ than citrus, $10-30 \%$ more than banana, and 10 times more than papaya. About $93 \%$ portion of guava fruit is edible [5]. Due to the high respiration rate, harvested guava attained a fast ripening stage and subsequently decayed incidence [6-10]. 
A passive barrier that delays the environmental effects on food products is known as adequate food packaging. Researchers are currently developing such a packaging material that positively impacts the environment and food, but it would also have good preservation properties [11]. The packaging with antimicrobial or antioxidant properties is proved to play an essential role in the stability of fresh food but extends its shelf life too [12]. The edible coating based on chitosan is derived from natural sources by deacetylation of chitin. Studies have shown that it is harmless to humans, wildlife, pets, and the environment.

Furthermore, it is effective for inhibiting the decay of fruits and extending shelf life [1314]. Previous studies have documented that chitosan and its derivatives-based coatings are efficient in inhibiting a wide range of fungi (Aider, 2010; No et al., 2007). The pathogen's damage caused in fruits and plants is minimized as chitosan-based coating triggers the defensive mechanisms. The studies focused on postharvest properties have documented that chitosan is active in inhibiting fungal growth in strawberries [15-16]. The coating on strawberries has reported its low levels do not change the fruit's astringency, and its coating does not alter consumer acceptance of strawberries in storage [17]. In another research Devlieghere et al. [18] have observed that chitosan-based coating not only reduced the propagation of harmful germs and pathogens, but it effectively affected the decay of fruits during storage.

In our previous study [4], the use of aloe vera (AV) based coating has proved effective in maintaining nutrition and extends the shelf life of guava fruits. In the current study, chitosan with different levels $(0.5,1.0,1.5,2.0 \%)$ was applied on guava stored for 12 days at room and refrigerated temperatures. The results would be useful for further development and edible coating materials.

\section{Materials and Methods}

\subsection{Sample collection}

The commercial cultivar of guava 'Gola" was selected, and samples were collected from the orchard of Ayub Agriculture Research Institute Faisalabad, Pakistan $\left(30^{\circ} 31^{\prime} 5^{\prime \prime} \mathrm{N}\right.$, $73^{\circ} 74^{\prime} 0^{\prime \prime} \mathrm{E}, 184 \mathrm{~m}$ above sea level) having tropical weather conditions. The fruits of same cultivar, full green color, and firm maturity were selected. The selection criteria include fruits free from injury, damage, or infection with insects, and the guava samples were uniform in size, shape, and color.

\subsection{Preparation of chitosan solutions}

The stock solutions of chitosan were prepared following the method Chen et al. [19]. Chitosan (Sigma-ID 448869-250G; degree of deacetylation $\geq 75$, MW: 50-190 kDa,) was used to prepare $500 \mathrm{ml}$ solution, $0,0.5,1,1.5$, and $2 \%(\mathrm{w} / \mathrm{v})$, taking the accurate weight of 2.5, 5.0, 7.5 and $10 \mathrm{~g}$ of chitosan in a volumetric flask and diluted up to $500 \mathrm{ml}$ with distilled water and added glacial acetic acid $(3 \mathrm{~mL})$, placed in a water bath for 15 minutes until it was properly mixed and cooled down at room temperature.

\subsection{Treatment of guava fruits}

A total of five groups of guava fruits were distributed into five groups containing each with 20 fruits. Each group's fruits were dipped into chitosan solutions (control, $0.5 \%, 1.0 \%, 1.5 \%$, and $2.0 \%$ for 2 minutes, respectively, and each treatment was performed in triplicate. Treated guavas fruits were dried for $30 \mathrm{~min}$ at room temperature and stored in sintered polyurethane plastic bags $(33 \mathrm{~cm} \times 25 \mathrm{~cm}, 10 \mathrm{~cm})$ and stored up to 
12 days at room temperature $\left(25^{\circ} \mathrm{C}\right.$ and at refrigerated temperature $4{ }^{\circ} \mathrm{C}$. The quality parameters and shelf-life attributes were calculated after 3 days intervals.

\subsection{Determination of total soluble solids (TSS)}

All treatments, including control of guava fruits, were converted into juices. The total soluble solids were calculated using a digital hand Refractometer (PAL-1, Atago, Tokyo, Japan) and expressed in terms of ${ }^{\circ}$ Brix.

\subsection{Total sugars, reducing sugar, and non-reducing sugar}

The amount of total sugar, reducing sugar, and non-reducing sugar was determined using our previously validated method [4]. Briefly, a sample of $0.5 \mathrm{~mL}$ was mixed with $0.25 \mathrm{~mL}$ phenol and added $1.25 \mathrm{~mL}$ of $\mathrm{H} 2 \mathrm{SO} 4$ (conc), and placed in a water bath at $30^{\circ} \mathrm{C}$ for 25 mint. The absorbance of the sample was noted at $490 \mathrm{~nm}$. The amount of reducing sugar in the juice was estimated by the method of 3,5 dinitrosalicylic acid (DNS) method. The Juice sample $200 \mu \mathrm{L}$ was extracted with $1 \mathrm{~mL}$ of DNs and $1.8 \mathrm{~mL}$ of distilled water. Then the solution was kept in a water bath for $15 \mathrm{mint}$ at $100{ }^{\circ} \mathrm{C}$. Finally, the solution was allowed to cool, and added $9 \mathrm{~mL}$ of distilled water and absorbance was noted at $540 \mathrm{~nm}$. However, the non-reducing sugar was calculated by subtracting the value of reducing sugar from total sugar.

\subsection{Determination of Malondialdehyde (MDA)}

The estimation of the lipid peroxidation level in the guava juices was determined using the thiobarbituric acid (TBA) method $[4,20]$. The absorbance was measured at $532 \mathrm{~nm}$ and $600 \mathrm{~nm}$.

\subsection{Detection of Vitamin C, total phenolic contents (TPC), and total flavonoids (TF)}

The detection of vitamin C (ascorbic acid) was carried as described by Hameed et al. [21]. The juice sample of $100 \mu \mathrm{L}$ was mixed with $900 \mu \mathrm{L}$ of distilled water. Then 100 $\mu \mathrm{L}$ of metaphosphoric acid and $100 \mu \mathrm{L}$ of dichloroindophenol (DCIP) were added to the solution and mixed properly. The ascorbic acid content in the supernatant was measured by the dinitrophenylhydrazine method.

The assessment of total phenolic content (TPC) was done by Folin-Ciocalteu (F-C) colorimetric method as described by Nair et al. [22]. The TPC concentrations were expressed as $\mu \mathrm{M} / \mathrm{g}$.

The detection of total flavonoids (TF) in guava juices was done as described by Lin and Tang [23]. The guava juice samples were diluted with aluminum chloride ( $\mathrm{AlCl} 3)$ and potassium acetate $(\mathrm{CH} 3 \mathrm{CO} 2 \mathrm{~K})$. The standard linear curve of quercetin and rutin with a range of $0.005-0.1 \mathrm{mg} / \mathrm{mL}$ was used to detect flavonoids, and the amount was expressed as $\mathrm{mg} / \mathrm{g}$ of fruit extract.

\subsection{HPLC detection of quercetin and rutin}

\subsubsection{Preparation of Sample for Flavonoid Analysis}

The quercetin $(\geq 95 \%, 100 \mathrm{~g}$, Sigma-Aldrich, USA) and rutin $(\geq 94 \%, 50 \mathrm{~g}$, Sigma-Aldrich, USA) were purchased. The standard curve of range from $0,10,20,50,100,200$, and 300 $\mu \mathrm{g} / \mathrm{mL}$ ) were prepared in methanol. The limit of quercetin and rutin detection was 0.09 and $0.10 \mu \mathrm{g} / \mathrm{g}$, respectively, and the limit of quantitations was 0.028 and $0.31 \mu \mathrm{g} / \mathrm{g}$, respectively. 
The sample of $10 \mathrm{~mL}$ of guava juice was extracted with $25 \mathrm{~mL}$ of methanol and sonicated for $20 \mathrm{~min}$. After sonication, the sample was centrifuged at 10,000 rpm for 10 minutes at $25^{\circ} \mathrm{C}$ [24]. Then, methanol $5 \mathrm{~mL}$ was added and again subjected to centrifugation at 10,000 rpm for 5 minutes. Then, the solution was filtered with Whatman (no 42) filter paper. Then $5 \mathrm{~g}$ of sodium sulfate anhydrous was added, and finally, the solution was filtered with a microsyringe filter $(0.45 \mu \mathrm{m}$, Merck) for further HPLC analysis.

\subsubsection{HPLC conditions}

The analysis of quercetin and rutin was conducted using HPLC (Model LC-10A) Shimadzu, Kyoto, Japan, with UV-Vis detector (SPD 10-A ( $\lambda 360 \mathrm{~nm}$ ). The mobile phase consisted of two solvents (A: 3\% trifluoroacetic acid (TFA) and B: acetonitrile and methanol $(80: 20 \mathrm{v} / \mathrm{v})$. The isocratic mode of both A and B mobile phases with the equal mixture $(50: 50 \mathrm{v} / \mathrm{v})$ was used for the separation of quercetin and rutin at a flow rate of 0.8 $\mathrm{mL} / \mathrm{min}$; (pressure: $67 \mathrm{~kg} / \mathrm{cm} 2$; injection volume: $20 \mu \mathrm{L}$; column temperature: $30{ }^{\circ} \mathrm{C}(\mathrm{CTO}$ 10-A); analytical column: C18 (250 × $4.6 \mathrm{~mm}, 5 \mathrm{~mm}$ particle size, Supelco, Bellefonte, PA, USA); delivery pump: LC-10AS; system controller: SCL-10A; acquisition software: CLASS LC-10.

\subsection{Determination of crude fiber, potassium, and sodium levels}

The crude fiber in guava juice was determined by AOAC method 962.09. Briefly, sample $3 \mathrm{~g}$ of juice was mixed in $5 \mathrm{~mL}$ of $1.25 \%$ sulfuric acid and heated at $100{ }^{\circ} \mathrm{C}$ for 30 minutes. Then, the solution was cooled and filtered by Whatman filter paper No. 42. The $2 \mathrm{~mL}$ of $1.25 \% \mathrm{NaOH}$ was added to the residue and mixed. Finally, the residue was ignited in the furnace at $600{ }^{\circ} \mathrm{C}$. The crude fiber was calculated using the following formula

Crude fiber $=\frac{\text { Weight of residue-weight of ash }}{\text { weight of the sample }}$

The estimation of potassium and sodium was done as the method described [25]. A stock solution of potassium from potassium chloride $100 \mu \mathrm{g} / \mathrm{mL}$ was prepared, and similarly, $100 \mu \mathrm{g} / \mathrm{mL}$ stock solution of $\mathrm{Na}$ sodium chloride was prepared. The standard curves included a range of $0,5,10,15,20$, and $25 \mu \mathrm{g} / \mathrm{mL}$ for further calculations.

\subsection{Statistical analysis}

The data results were subjected to statistical analysis using SPSS (version 26 for Windows, SPSS Inc., Chicago, USA). The normality of data was analyzed using a normal distribution (Shapiro-Wilks test). To investigate the difference in treatment means and different storage temperatures, ANOVA was applied. The least significant difference (LSD) was used to analyze the difference of treatment during the storage period. A probability value of 0.05 was used to determine the statistical significance.

\section{Results and discussion}

The influence of chitosan coating on guava fruit stored at room and refrigerated temperature is shown in Fig 1. 


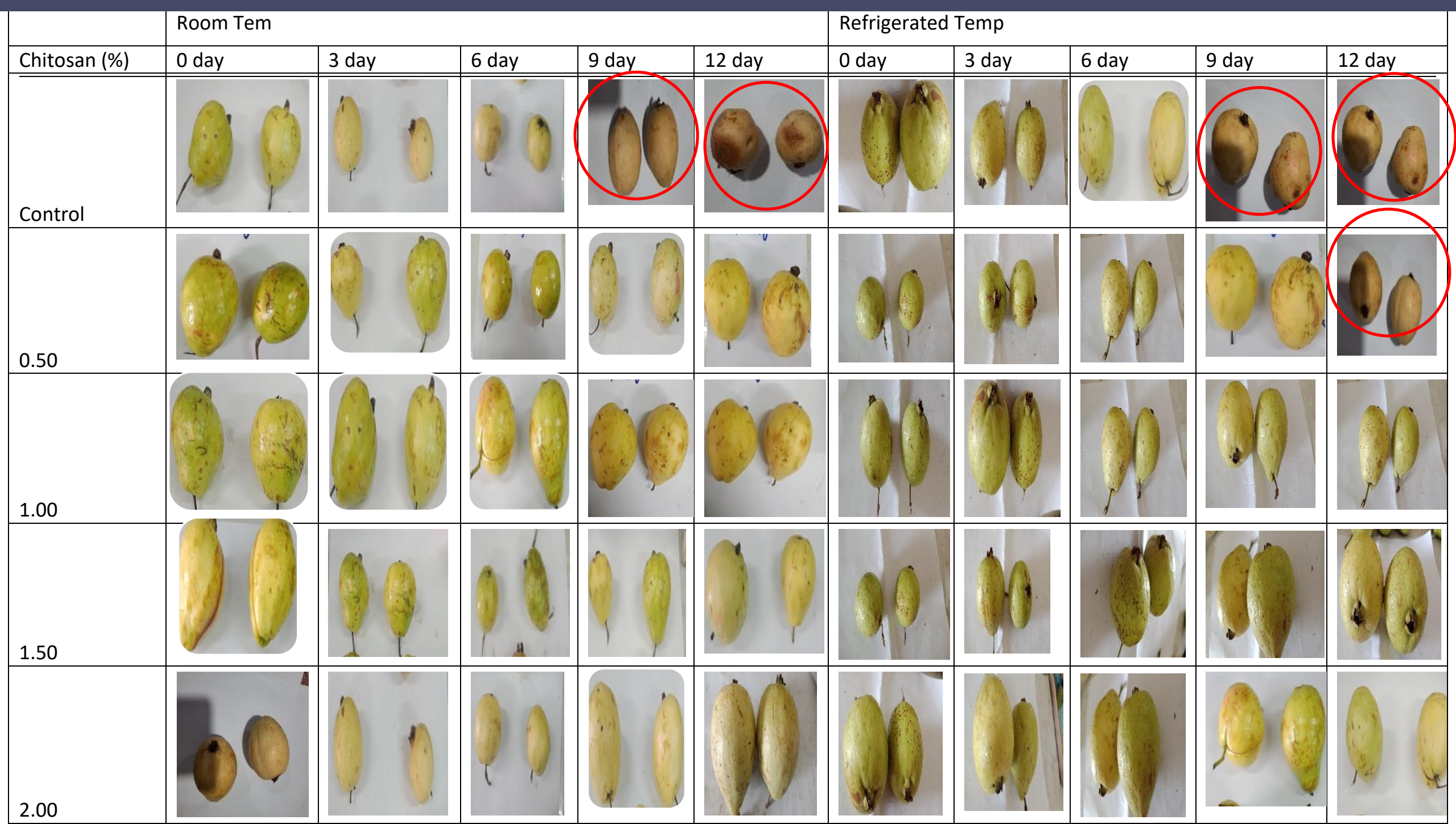

Fig 1: Photographs of control, $0.50 \%$ chitosan, $1 \%$ chitosan, $1.5 \%$ chitosan, and $2 \%$ of chitosan-coated fruits at the 0 th, $3^{\text {rd }}, 6^{\text {th }}, 9^{\text {th }}$ and 12 th day of storage at room and refrigerated temperature 


\subsection{Total soluble solids (TSS)}

The amount of total soluble solids (TSS) in guava fruits with different chitosan treatments at room and refrigerated temperatures is shown in Fig 2. In control samples stored at room temperature, TSS levels were gradually decreased except on the 6th day (increased from 10 to $11^{\circ}$ Brix). The highest increase of TTS levels (16.02 to 17.2 and 16.5 to $17.2^{\circ}$ Brix) was observed at 12 th-day storage (refrigerated temperature) at chitosan treatments of $1.5 \%$ and $2.0 \%$, respectively. In chitosan treatment, guava samples both stored at room temperature and refrigerated temperature

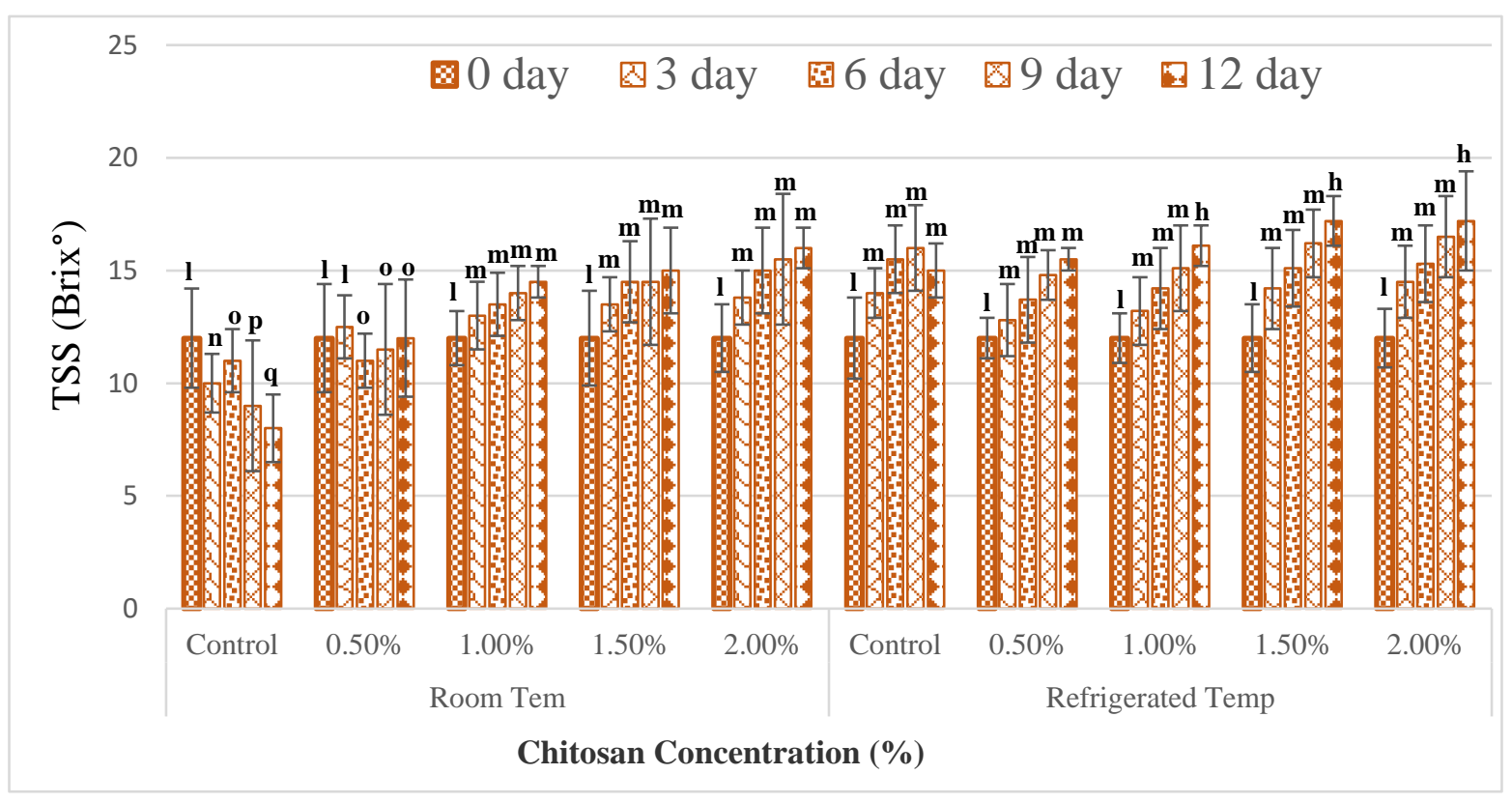

Fig.2: Impact of chitosan treatments on total soluble solids of guava fruit at room temperature.

Values are the mean of three replicates, and vertical bars show the standard errors.

\subsection{Levels of TS, RS and NRS}

The presence of sugars in guava fruit imparts sweetness which directly linked the flavor and taste of fruit. The influence of chitosan treatments at room and refrigerated temperature on total sugars (A), reducing sugars (B), and non-reducing sugars (C) is represented in Fig 3. The levels of total sugars in control (room temperature) were increased from 210.5 to $295.5 \mathrm{mg} / \mathrm{g}$, and in control (refrigerated temperature) increased from 211.5 to $270.5 \mathrm{mg} / \mathrm{g}$ (Fig 3A). However, with chitosan treatment, levels insignificantly decrease the levels of total sugars (room temperature storage period) or retain the levels of total sugars in guava fruits (refrigerated temperature) samples. The total sugar levels were significantly different in samples stored at room temperature compared to samples stored at refrigerated temperature $(\mathrm{p} \leq 0.05)$. The levels of reducing sugars also increased in control samples from 125.5 to $159.7 \mathrm{mg} / \mathrm{g}$ (stored at room temperature), and 125.5 to $155.5 \mathrm{mg} / \mathrm{g}$ (stored at refrigerated temperature)

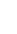

.

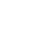

.



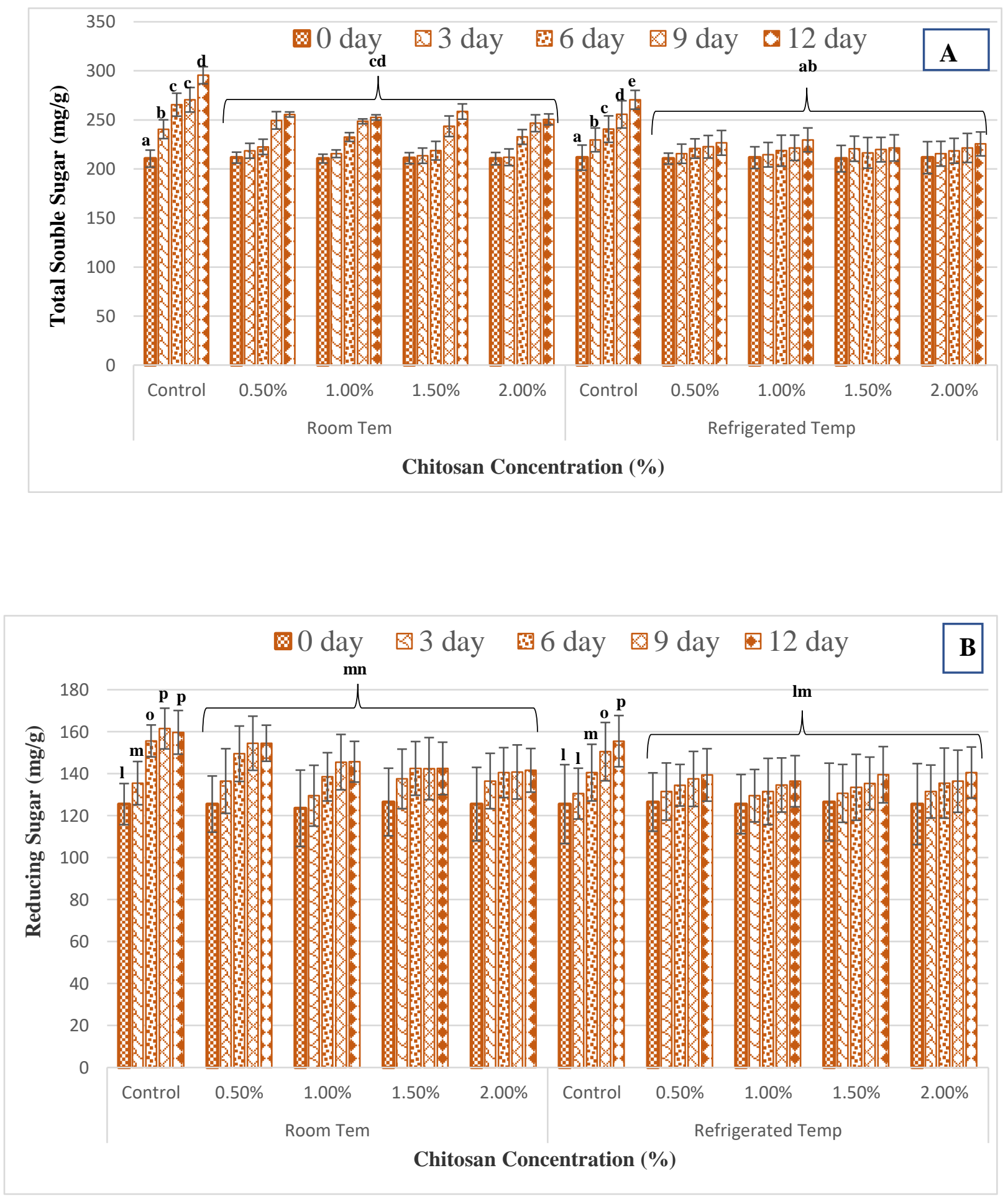

The results have shown a significant difference in reducing sugars in samples stored at room temperature than the samples stored at refrigerated temperature $(\mathrm{p} \leq$ 0.05). The levels of non-reducing sugars were decreased from $80.5 \mathrm{mg} / \mathrm{g}$ to $55.6 \mathrm{mg} / \mathrm{g}$ at the 9th day storage period in samples of control stored at room temperature but increased from 55.6 to $81.5 \mathrm{mg} / \mathrm{g}$ at 12-day storage period (Fig 3C). The maximum increase $(75.6$ to $85.6 \mathrm{mg} / \mathrm{g})$ in the levels of non-reducing sugars was observed on the 9 th day stored at room temperature of chitosan treatment of $1.5 \%$. However, the results have shown a nonsignificant difference in non-reducing sugars in samples stored at room temperature compared to the samples stored at refrigerated temperature. A similar trend in the levels of total sugar, reducing sugar and non-reducing 
sugars, was observed when treated with different coating levels with AV gel in guava fruit [4]. They have documented a maximum increase with AV gel $40 \%$ and corresponded to $93 \mathrm{mg} / \mathrm{g}$ on the 12th day, and the treatment of $80 \% \mathrm{AV}$ gel has retained the level of non-reducing sugars from 0 days to the 12 th day ( 85 to $87 \mathrm{mg} / \mathrm{g}$ ). The studies have shown that sugar concentration increases during the ripening stage and senescence of fruits. The conversion of starch may also contribute to the rise in the level of sugar. The coating of chitosan inhibits the ripening stage, subsequently the senescence and conversion of starch into sugars [29]. Our results are following previous findings in guava obtained in China [30]. A similar conclusion regarding total sugar levels, reducing sugar, and non-reducing sugar were achieved using $\mathrm{CaCl} 2$ treatments during storage of guava [27]. Guava fruits coated with the $80 \%$ AV gel displayed a lower increase in sugar content, which may be due to the gel's ability to slow down the starch's conversion into sugars.

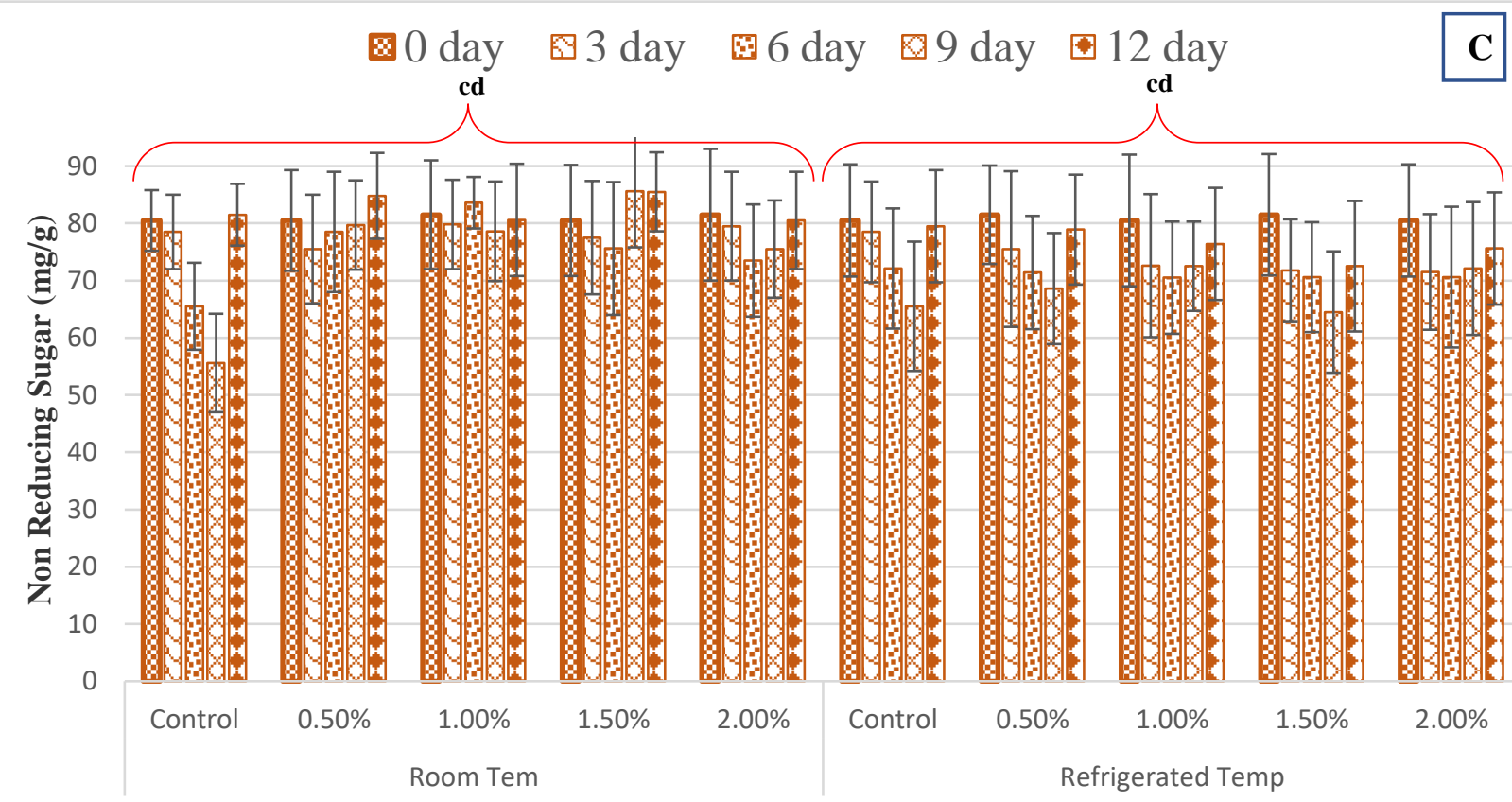

Chitosan Concentration (\%)

Figure 3: Effect of chitosan treatments on total soluble sugars (A); reducing sugars (C) and nonreducing sugars at room and refrigerated temperatures.

The different English letter represents the levels have significantly different $(\mathrm{p} \leq 0.05)$

\subsection{Lipid peroxidation Malondialdehyde (MDA) content}

The increase in the levels of malondialdehyde (MDA) levels is an indication of damage or injury of fruits or rapture of the membrane due to oxidation of lipids into MDA [20]. The results have shown a significant increase $(p \leq 0.05)$ in MDA levels in guava samples stored at room temperature (increased 10 to $28 \mu \mathrm{M} / \mathrm{g}$ from 0 days to 12th day period), and in refrigerated temperature (increased 6 to 22 $\mu \mathrm{M} / \mathrm{g}$ from 0 to 12 th day storage period) Fig. 4 . However, the MDA levels were significantly different $(\mathrm{p} \leq 0.05)$ in samples stored in refrigerated temperature periods than the samples stored in room temperature storage. The doses of $1.5 \%$ and $2.0 \%$ of chitosan on guava samples stored at room temperature were effective to minimize the levels of MDA formation. A similar finding was documented when 
guava samples were treated with different concentrations of AV gel in the storage period and found that $60 \%$ and $80 \%$ AV gel treatments were more effective in reducing MDA levels and thus suppressing the damage of fruits [4]. Hong et al. [31] have observed similar results, which reinforce the current study's finding.

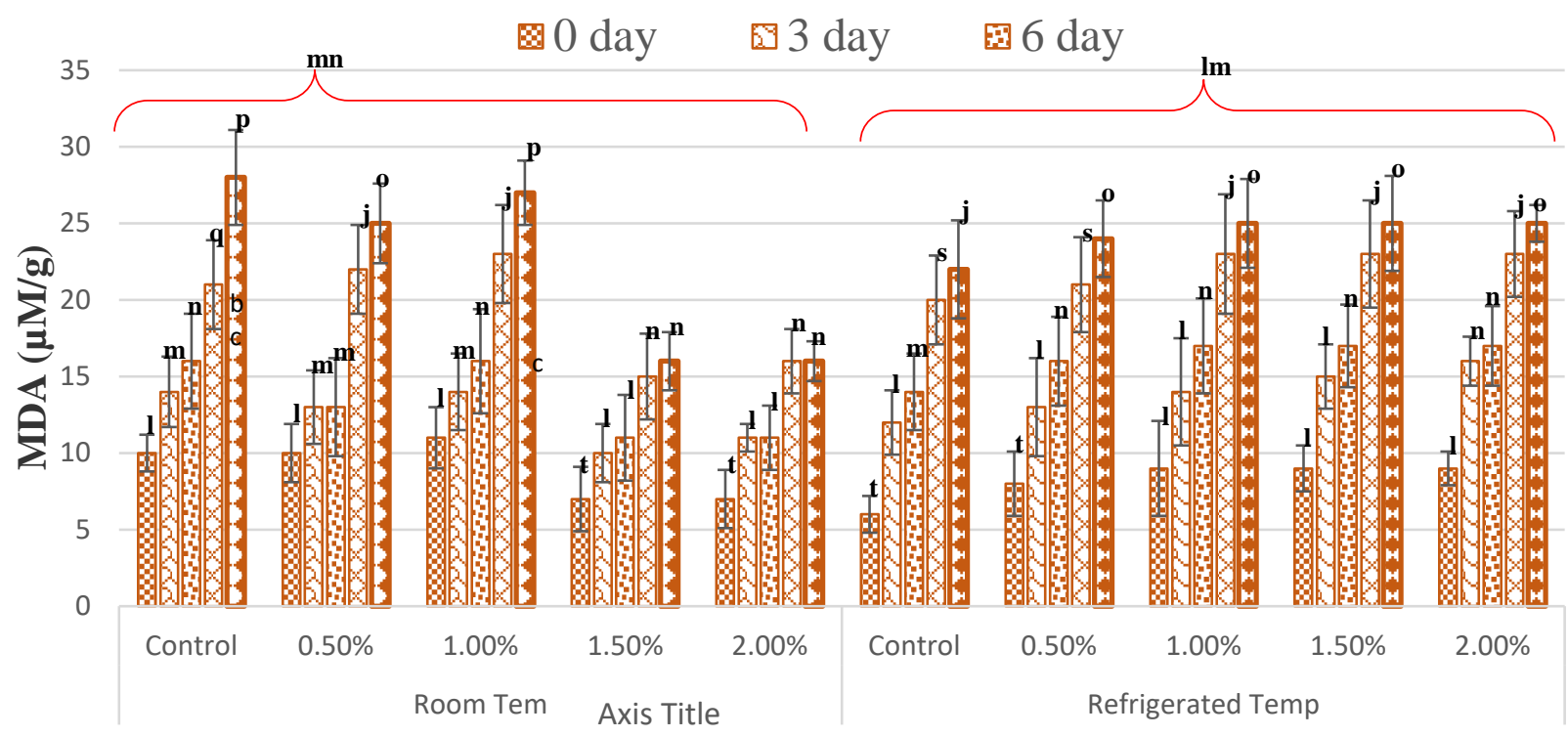

Fig 4: The influence on MDA $(\mu \mathrm{M} / \mathrm{g})$ levels with different treatments of chitosan in guava samples stored at room and refrigerated temperatures.

\subsection{Vitamin C, total phenolic contents (TPC), total flavonoids (TF), and rutin levels}

The vitamin C (Ascorbic acid (AsA) is an important antioxidant in guava fruit. It acts as an antioxidant and inhibits free radicals during oxidation, thus preventing the deterioration of fruits. The levels of AsA decreased significantly $(p \leq 0.05)$ in control samples (room temperature) Fig. 5A. However, the samples treated with different doses of chitosan have minimized the decrease of AsA levels in room and refrigerated stored guava samples. The reduction of AsA during storage might be explained due to the oxidative breakdown [32]. In the current study, the coating of guava with 1.5 and $2 \%$ chitosan during refrigeration temperature was more effective in retaining the levels of AsA. Khaliq et al. [33] have observed that fruits coated with AV gel inhibit oxidation, limiting the reduction of AsA during the postharvest period because it blocks the availability of $\mathrm{O} 2$ during oxidative breakdown. The influence of different treatments of chitosan levels on the amount of total phenolic content (TPC) at different storage periods and temperatures is shown in Fig. 5B. The levels of TPC were significantly decreased $(\mathrm{p} \leq 0.05)$ during control samples stored at room temperatures. However, the coating with 1.5 and $2 \%$ of chitosan samples was found effective to retain TPC levels in stored guava samples even at the 12 th day storage period. There is a significant $(p \leq 0.05)$ difference in TPC levels treated with various levels of chitosan stored at room compared to refrigerated temperature. Phenolics compounds are recognized as secondary metabolites which possess the antioxidants activity and inhibit the formation of free radicals during oxidation and thus maintain the nutritional levels intact [34].

105 

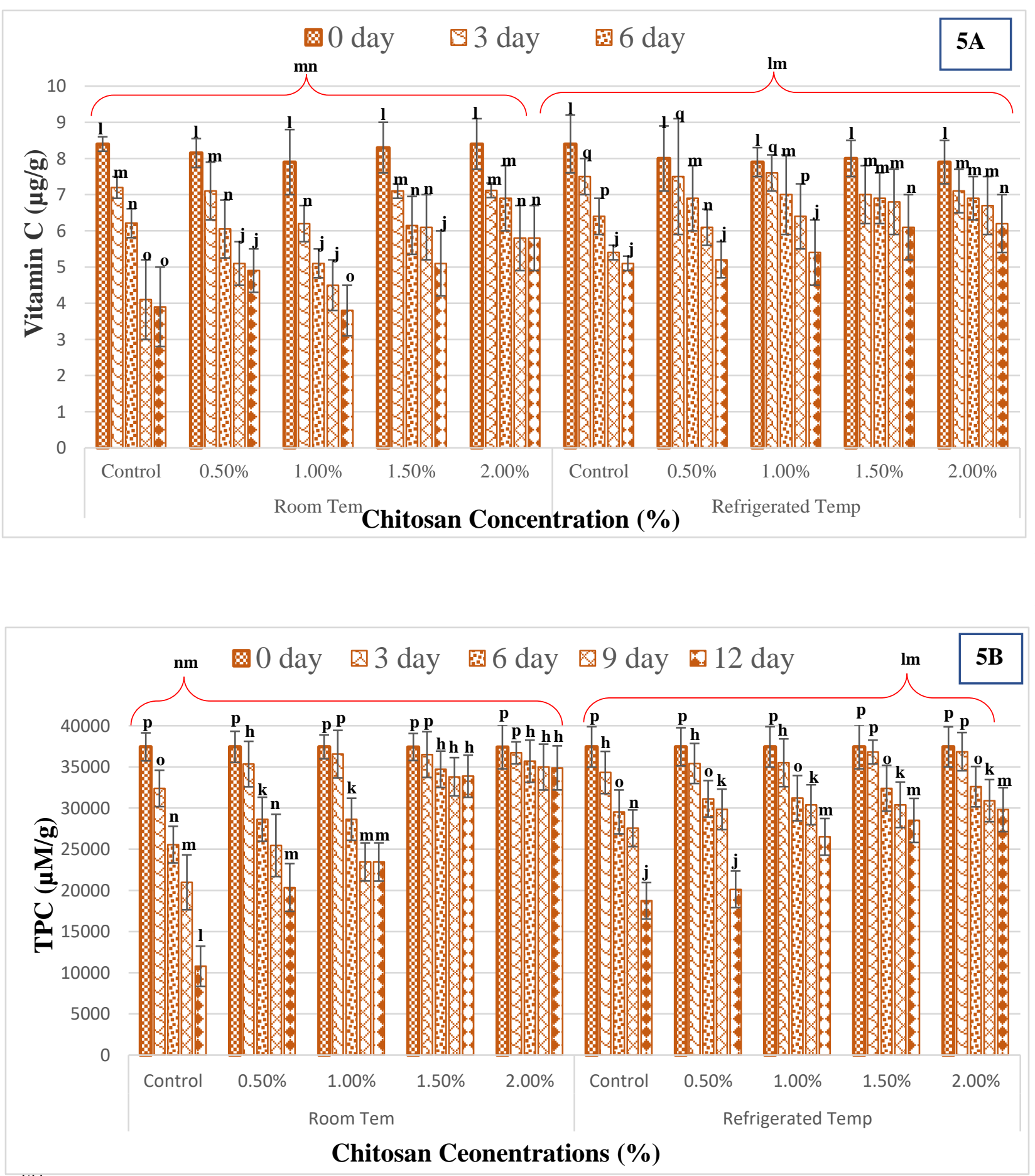

These results of the present research are in agreement with results documented by Chidtragool et al.[35] who worked on phenolic contents and their inhibition ability of free radicals during the storage and ripening period of fruits. In another report, gabiroba fruit grown in Brazil and stored at different temperatures have shown similar trends [36]. In another study decrease in TPC levels were reported in litchi fruit [37]. 

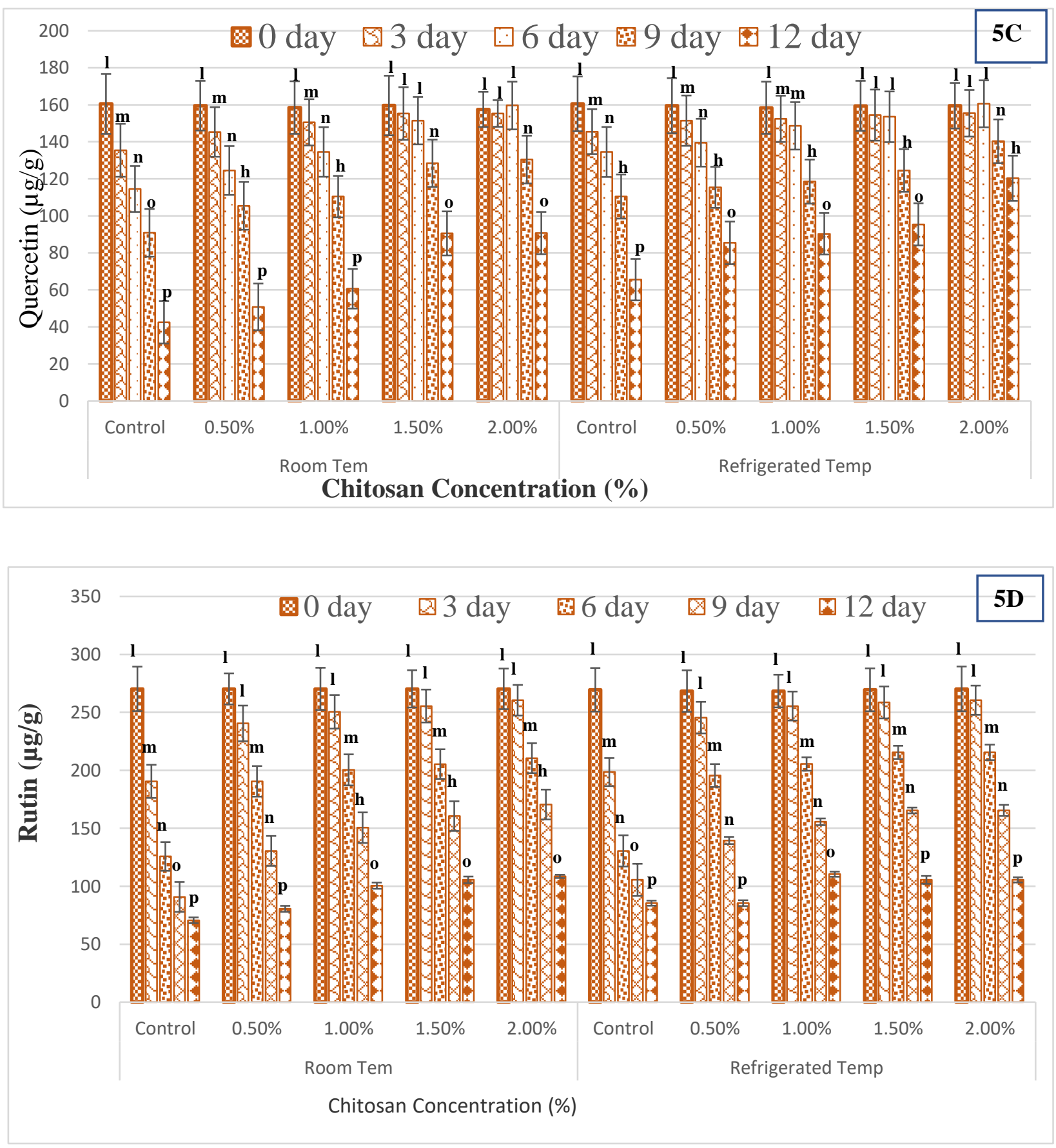

Fig.5: Impact of chitosan treatments on vitamin C (A), total phenolic content (B), quercetin level (C), and rutin (D) levels in guava fruit stored at room and refrigerated temperature.

The levels of total flavonoids (Quercetin) $\mu \mathrm{g} / \mathrm{g}$ and rutin $(\mu \mathrm{g} / \mathrm{g}$ ) after applying different levels of coating with chitosan in guava fruits at different stored temperatures are shown in Fig 5C and 5D.

The levels of quercetin and rutin were decreased significantly $(p \leq 0.05)$ during all storage periods. However, the decrease was slow in samples treated with chitosan-based coating compared to those with control samples. The level of quercetin was decreased from 160.5 to $42.5 \mu \mathrm{g} / \mathrm{g}$ in guava samples of control stored at room temperature. The rutin level was reduced from 270.3 to $70.6 \mu \mathrm{g} / \mathrm{g}$ in control samples stored at room temperature conditions. Chitosan coating with 1.5 and $2.0 \%$ treatments also resulted in decreased levels of quercetin and 
rutin during all storage periods. Both these compounds' importance could be known due to their use as ingredients in various multivitamin supplements [38]. The phenolics and flavonoids' mechanism both react with hydroxyl radicals and superoxide anion radicals [39-40]. Chitosan coating on guava fruits facilitates the induction of phenylalanine ammonia-lyase pathway in fruit, which might be responsible for maintaining a high level of flavonoid content for a more extended period [41]. These findings are in close agreement with the results from other studies, which applied different coatings on fruits and found them adequate for maintaining or preserving the levels of flavonoids in papaya [42], and in tomato [43]. The findings of current research demonstrated that the doses of 1.5 and $2.0 \%$ chitosan treatments effectively maintain the levels of flavonoids and rutin.

\subsection{Crude fiber, potassium, and sodium levels}

The levels of crude fiber (Fig 6A), potassium (Fig 6B), and sodium (6C) were determined and observed the influence of chitosan coating in guava fruits

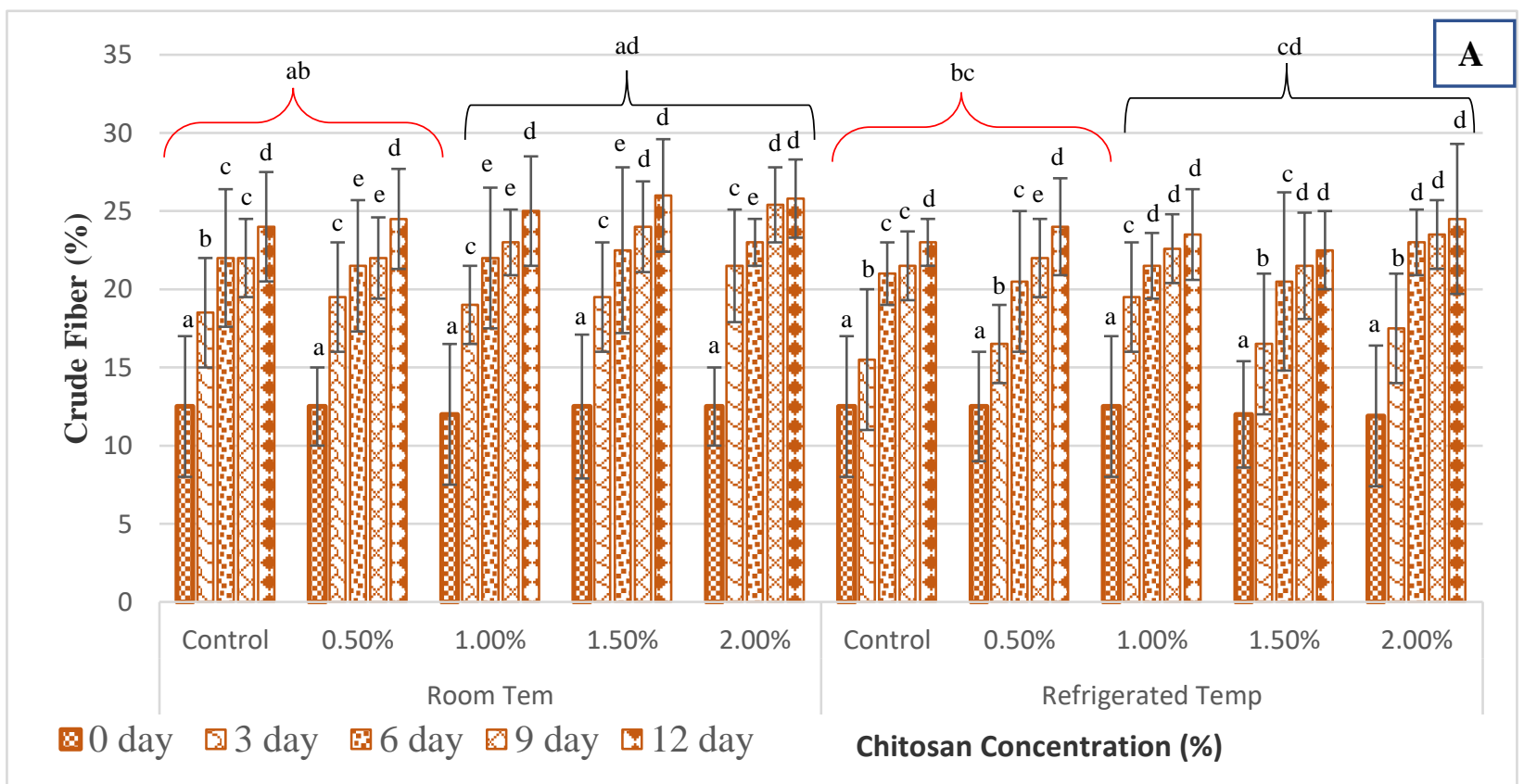

in room and refrigerated storage temperatures. The levels of crude fibers were insignificantly increased during the storage period, and levels were significantly different $(\mathrm{p} \leq 0.05)$ in samples of guava of control and $0.50 \%$ chitosan treatment stored at room temperature compared to the samples stored in refrigeration temperature conditions. The potassium levels in different treatments and stored at room and refrigerated storage temperatures were statistically insignificant ( $\mathrm{p} \leq 0.05)$, Fig. 6B. Similar trends were observed in Fig. 6C, where sodium levels after applying different chitosan treatments were nonsignificant $(p \leq 0.05)$ stored at room and refrigerated storage temperature. The presence of potassium and sodium in fruits has various health benefits, including reducing blood pressure and inflammation and controlling blood sugar levels. The results have shown no significant change in the concentration of crude fiber, potassium and sodium levels after treatment with various chitosan coating levels in guava fruit. The small variation might be explained due to differences in a cultivar of fruit, soil variation, and irrigation of water [44]. 

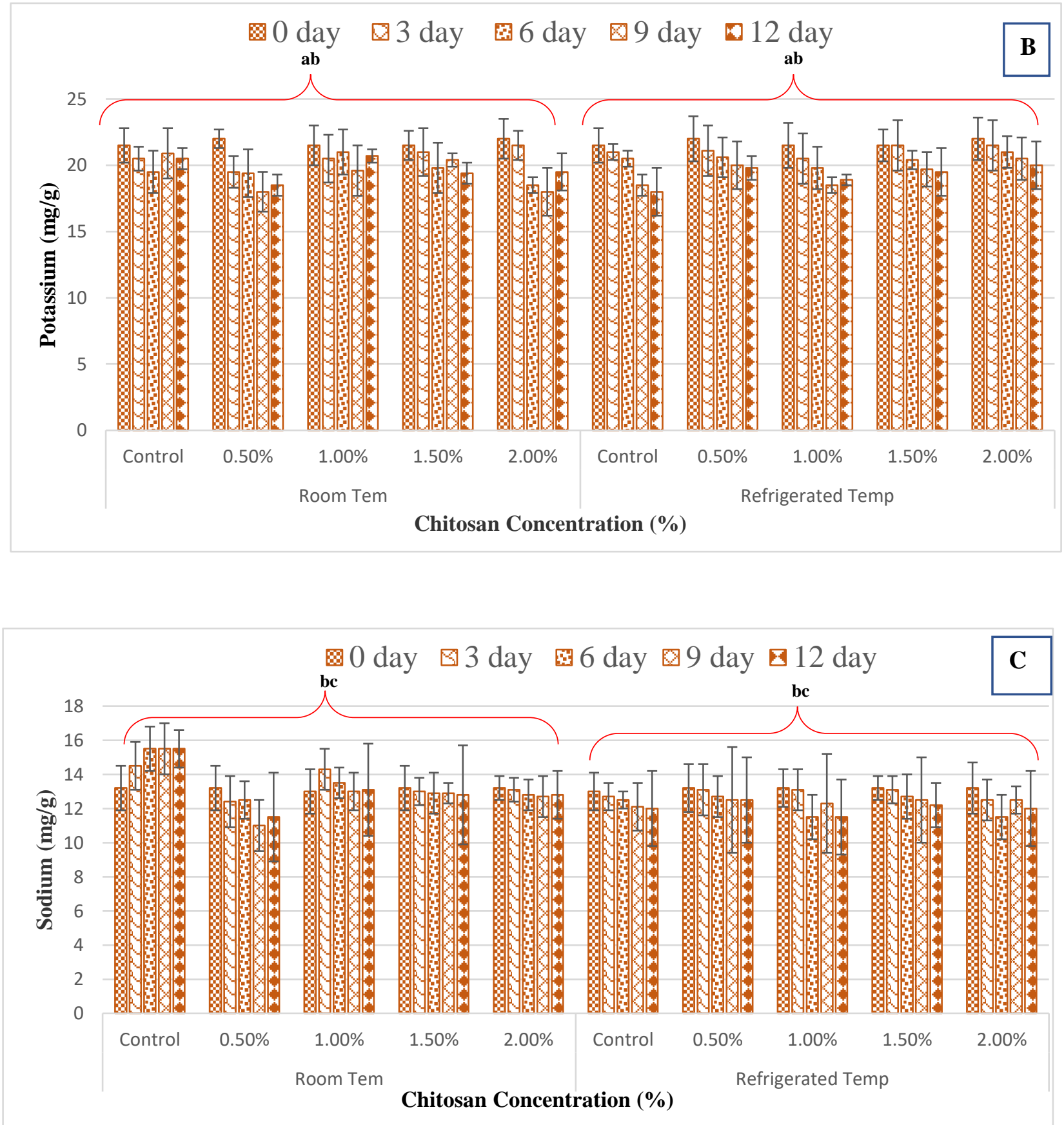

Fig.6: Impact of chitosan treatments on crude fiber (A), potassium level (B), and sodium level (C) in guava fruit stored at room and refrigerated temperature.

\section{Conclusions}

The results of present study have documented that the natural edible coating has great potential in food packaging and food preservation. The chitosan coating in guava fruits have shown reducing in the levels of total sugars and lipid oxidation compared to controlled untreated samples. Furthermore, the chitosan treated samples have maintained levels of total phenolics, flavonoids, and vitamin C levels compared to controlled samples. The samples treated with chitosan and stored at refrigerated temperature have shown significant difference compared to samples stored at room temperature. The coating with chitosan with 1.5 and $2.0 \%$ treatments have more efficient results in extending shelf life and maintaining nutritional qualities of guava fruits. 
Funding: The research was not funded externally but supported by NIAB, Faisalabad,
Jang Road Faisalabad.

Conflict of Interest: The authors declare no conflict of interest.

\section{References}

1. Mitra, S.K.; Irenaeus, T.K.S.; Gurung, M.R.; Pathak, P.K. Taxonomy and importance of Myrtaceae. Acta Hortic. 2012, 959, 23-34.

2. Padilla-Ramirez, J.S.; González-Gaona, E.; Ambriz-Aguilar, J. International market of fresh and processed guava: Challenges and perspectives for the Mexican case. Acta Hortic. 2012, 959, 15-21.

3. Shah, M.H.; Usman, M.; Fatima, B.; Nawaz-Ul-rehman, M.S. Assessment of guava wilt disease (GWD) and varietal susceptibility in Punjab-Pakistan. Pak. J. Agric. Sci. 2019, 56, 393-399.

4. Rehman, M.A.; Asi, M.R.; Hameed, A.; Bourquin, L.D. Effect of Postharvest Application of Aloe Vera Gel on Shelf Life, Activities of Anti-Oxidative Enzymes, and Quality of 'Gola' Guava Fruit. Foods 2020, 9, 1361; doi:10.3390/foods9101361

5. Haque, M.N.; Saha, B.K. M.; Karim, R.; Bhuiyan, M.N.H. Evaluation of Nutritional and Physico-Chemical Properties of Several Selected Fruits in Bangladesh. Bangladesh. J. Sci. Ind. Res. 2009, 44(3), 353-358.

6. Murmu, S.B.; Mishra, H.N. Post-harvest shelf-life of banana and guava: Mechanisms of common degradation problems and emerging counteracting strategies. Innov. Food Sci. Emerg. Technol. 2018, 49, $20-30$.

7. Singh, N.; Misra, K.K.; Dongariyal, A.; Rani, A.; Nirgude, V. Response of different coating material on post-harvest life and quality of guava (Psidium guajava L.). Int. J. Chem. Stud. 2018, 6, 2635-2639.

8. Nasima, N.; Swaminathan, V.; Rajangam, J.; Venkatesan, K. Response of post-harvest dipping on shelf-life and quality of guava (Psidium guajava L.) fruits under cold storage. Int. J. Chem. Stud. 2019, 7, 1901-1905.

9. Blancas-Benitez, F.J.; González-Aguilar, G.A.; Sáyago-Ayerdi, S.G. Guava (Psidium guajava); Yahia, E.M., Ed.; Wiley Online Library: Hoboken, NJ, USA, 2017; pp. 1067-1076.

10. Hong, K.; Xie, J.; Zhang, L.; Sun, D.; Gong, D. Effects of chitosan coating on postharvest life and quality of guava (Psidium guajava L.) fruit during cold storage. Sci. Hortic. (Amsterdam) 2012, 144, 172-178.

11. Elsabee, M. Z.; Abdou, E. S. Chitosan based edible films and coatings: A review. Mater. Sci. Eng. C. 2013, 33, 18191841.

12. Khalifa, I.: Barakata, H.: El-Mansy, H. A.: Soliman, S. A. Improving the shelf life stability of apple and strawberry fruits applying chitosan-incorporated olive oil processing residues coating. Food Packag. Shelf Life, 2016, 9, 10-19.

13. Aider, M. Chitosan application for active bio-based films production and potential in the food industry: review. LTW-Food Sci. Technol. 2010, 43, 837-842.

14. No, H. K.; Meyers, S. P.; Prinyawiwatkul, W.; Xu, Z. Applications of chitosan for improvement of quality and shelf life of foods: a review. J. Food Sci. 2007, 72, R87-R100.

15. Han, C. Y.; Zhao, Y.; Leonard, S.W.; Traber, M.G. Edible coatings to improve storability and enhance nutritional value of fresh and frozen strawberries (Fragaria $x$ ananassa) and raspberries (Rubus ideaus). Postharvest Biol. Technol. 2004, 33, 67-78.

16. Zhang, D.; Quantick, P. Antifungal effects of chitosan coating on fresh strawberries and raspberries during storage. J. Hortic. Sci. Biotechnol. 1998, 73, 763-767.

17. Bautista-Baños, S.; Hernández-López, M.; Bosquez-Molina, E. Growth inhibition of selected fungi by chitosan and plant extracts. Mexican J. Phytopathol. 2004, 22, 178-186.

18. Devlieghere, F.; Vermeulen, A.; Debevere, J., Chitosan: antimicrobial activity, interactions with food components and applicability as a coating on fruit and vegetables," Food Microbiology, 2004, 21 (6), 703-714.

19. Chen, C.; Peng, X.; Chen, J.; Gan, Z.; Wan, C. Mitigating effects of chitosan coating on postharvest senescence and energy depletion of harvested pummelo fruit response to granulation stress. Food Chem. 2021, 348, 129113.

20. Sun, J.; You, X.; Li, L.; Peng, H.; Su, W.; Li, C.; He, Q.; Liao, F. Effects of a phospholipase D inhibitor on postharvest enzymatic browning and oxidative stress of litchi fruit. Postharvest Biol. Technol. 2011, 62, $288-294$.

21. Hameed, A.; Goher, M.; Iqbal, N. Drought induced programmed cell death and associated changes in antioxidants, proteases, and lipid peroxidation in wheat leaves. Biologia Plantarum 2013, 7(2), 370-374. 
22. Nair, M. S.; Saxenaa, A.; Kaur, C. Effect of chitosan and alginate based coatings enriched with pomegranate peel extract to extend the postharvest quality of guava (Psidium guajava L.). Food Chem. 2018, 240, $245-252$.

23. Lin, J.Y.; Tang, C.Y. Determination of total phenolic and flavonoid contents in selected fruits and vegetables, as well as their stimulatory effects on mouse splenocyte proliferation. Food Chem. 2007, 101, 140-147

24. Tewari, R.; Gupta, M.; Ahmad, F.; Rout, P.K.; Misra, L.; Patwardhan, A.; Vasudeva, R. Extraction, quantification and antioxidant activities of flavonoids, polyphenols and pinitol from wild and cultivated Saraca asoca bark using RP-HPLC-PDA-RI method. Ind. Crops Prod. 2017, 103, 73-80.

25. Vieira, E.; Soares, M.E.; Ferreira, I.; Pinho, O. Validation of a fast sample preparation procedure for quantification of sodium in bread by flame photometry. Food Anal. Methods 2012, 5, 430-434

26. Bexiga F.; Rodrigues D.; Guerra R, Brázio A.; Balegas T.; Cavaco A M.; Antunes M.D.; de Oliveira, J.V. A TSS classification study of 'Rocha' pear (Pyrus communis L.) based on noninvasive visible/near infra-red reflectance spectra. Postharvest Biol. Technol. 2017, 132 23-30.

Javed, M.S.; Randhawa, M.A.; Ahmad, Z.; Sajid, M.W.; Nasir, M.A.; Tariq, M.R. Effect of $\mathrm{CaCl}_{2}$ and controlled atmosphere storage on phytochemical attributes of Guava. Food Sci. Technol. 2018, 38, 356-362.

28. Gohlani, S.; Bisen, B.P. Effect of different coating material on the storage behaviour of custard apple (Annona squamosa L.). Bioscan J. 2012, 7, 637-640.

29. Ullah, A.; Abbasi, N.A.; Shafique, M.; Qureshi, A.A. Influence of edible coatings on biochemical fruit quality and storage life of bell pepper cv."Yolo Wonder". J. Food Qual. 2017, 1-11.

30. Chawla, S.; Devi, R.; Jain, V. Changes in physicochemical characteristics of guava fruits due to chitosan and calcium chloride treatments during storage. J. Pharmacogn. Phytochem. 2018, 7(3), 1035-1044.

31. Hong, K.; Xie, J.; Zhang, L., Sun, D.; Gong, D. Effects of chitosan coating on postharvest life and quality of guava (Psidium guajava L.) fruit during cold storage. Scientia Hortic. 2012, 144: 172-178.

32. Mditshwa, A.; Magwaza, L.S.; Tesfay, S.Z.; Opara, U.L. Postharvest factors a_ecting vitamin C content of citrus fruits: A review. Sci. Hortic. (Amst.) 2017, 218, 95-104.

33. Khaliq, G.; Mohamed, M.T.M.; Ding, P.; Ghazali, H.M.; Ali, A. Storage behaviour and quality responses of mango (Mangifera indica L.) fruit treated with chitosan and gum arabic coatings during cold storage conditions. Int. Food Res. J. 2016, 23, S141.

34. Shah, H.M.S.; Khan, A.S.; Ali, S. Pre-storage kojic acid application delays pericarp browning and maintains antioxidant activities of litchi fruit. Postharvest Biol. Technol. 2017, 132, 154-161.

35. Chidtragool, S.; Ketsa, S.; Bowen, J.; Ferguson, I.B.; van Doorn, W.G. Chilling injury in mango fruit peel: Cultivar differences are related to the activity of phenylalanine ammonia lyase. Postharvest Biol. Technol. 2011, 62, 59-63.

36. Silva, E.P.D.; Cardoso, A.F.L.; Fante, C.; Rosell, C.M.; Boas, V.; de Barros, E.V. Effect of postharvest temperature on the shelf life of gabiroba fruit (Campomanesia pubescens). Food Sci. Technol. 2013, 33, 632-637

37. Ali, S.; Khan, A.S.; Nawaz, A.; Anjum, M.A.; Naz, S.; Ejaz, S.; Hussain, S. Aloe vera gel coating delays postharvest browning and maintains quality of harvested litchi fruit. Postharvest Biol. Technol. 2019, 157.

38. Erlund, I.; Kosonen, T.; Alfthan, G.; Mäenpää, J.; Perttunen, K.; Kenraali, J.; Parantainen, J.; Aro, A. Pharmacokinetics of quercetin from quercetin aglycone and rutin in healthy volunteers. Eur. J. Clin. Pharmacol. 2000, 56, 545-553. Viera, V.B.; Piovesan, N.; Rodrigues, J.B.; de O Mello, R.; Prestes, R.C.; dos Santos, R.C.V.; de A Vaucher, R.; Hautrive, T.P.; Kubota, E.H. Extraction of phenolic compounds and evaluation of the antioxidant and antimicrobial capacity of red onion skin (Allium cepa L.). Int. Food Res. J. 2017, 24, 990-999.

40. Márquez, K.; Contreras, D.; Salgado, P.; Mardones, C. Production of hydroxyl radicals and their relationship with phenolic compounds in white wines. Food Chem. 2019, 271, 80-86.

41. Khalil, A.A.; Khan, M.R.; Shabbir, M.A. In vitro antioxidant activity and punicalagin content quantification of pomegranate peel obtained as agro waste after juice extraction. Pak. J. Agric. Sci. 2018, 55, 197-201.

Addai, Z.R.; Abdullah, A.; Mutalib, S.A. Influence of ripening stages on antioxidant properties of papaya fruit (Carica papaya L.). In AIP Conference Proceedings; American Institute of Physics: College Park, MD, USA, 2013; Vol. 1571, pp. 696-701.

43. Firdous, N.; Khan, M.R.; Butt, M.S.; Shahid, M. Application of aloevera gel based edible coating to maintain postharvest quality of tomatoes. Pak. J. Agric. Sci. 2020, 57, 245-249.

44. Ishaq, S. Effect of preservation techniques on the physico-chemical composition and antioxidant activity of edible plants (elaeagnus umbellate, sonchus oleraceus, mentha longifolia) from poonch azad jammu \& kashmir, University of Azad Jammu and Kashmir Muzaffarabad, Pakistan. 2013. 
